\title{
Cosmopolitismo y nación: Juguemos en el mundo de María Elena Walsh*
}

\author{
Verónica P. Pittau \\ [Universidad Nacional del Litoral]
}

\begin{abstract}
Resumen Juguemos en el mundo de María Elena Walsh fue espectáculo, dos discos, un libro, un film y un producto artístico que marcó el comienzo de su producción para adultos y fue representativo de la cultura popular cosmopolita de la argentina de finales de los sesenta. El disco consta de 12 canciones en las que convergen géneros nacionales e internacionales, interpretados por Walsh y un grupo que contó con arreglos de Oscar Cardozo Ocampo. Nos enfocaremos en dos canciones: Manubrio azul y El 45, que se caracterizan por su alto grado de intertextualidad. Con apoyo en los estudios sobre cultura popular y pospopular de Pablo Alabarces (2020), los abordajes estéticos sobre producciones cosmopolitas argentinas de Gonzalo Aguilar (2009) y la teoría literaria de Gerard Genette sobre hipertextualidad (1989), intentaremos comprender cómo estas canciones proponen una variante cosmopolita que representa musicalmente a la argentina de finales de los sesenta.
\end{abstract}

Palabras clave: música electroacústica . nacionalismo - cosmopolitismo - Córdoba · paisaje sonora
Summary Juguemos en el Mundo by María Elena Walsh (Bs. As. 1930-1911) was a show, two albums, a book, a film and an artistic product representative of the cosmopolitan popular culture of Argentina in the sixties. It consists of 12 songs in which national and international genres converge performed by María Elena Walsh (voice), in addition to Oscar Cardozo Ocampo arrangements. We will focus on two songs from the first album: Manubrio azul and El 45. With support from the studies on popular and post-popular culture by Pablo Alabarces (2020), the aesthetic approaches on Argentine cosmopolitan productions of Gonzalo Aguilar (2009) and the literary theory of Gerard Genette about hypertextuality (1989), we will try to understand how these are songs propose a cosmopolitan variant to musically represent Argentina in the late sixties.

Keywords: Electroacoustic Music . Nationalism · Cosompolitanism · Córdoba · Soundscape

\footnotetext{
* Trabajo elaborado en el marco del Proyecto CAI+D 2020 Procesos creativos en la canción popular argentina: composición, arreglo, versión e interpretación, dirigido por la Prof. Elina Goldsack, en el Instituto Superior de Música de la Universidad Nacional del Litoral (Santa Fe, Argentina).
} 
Este disco está dedicado a los chiflados que suponen que la música popular puede no ser necesariamente pachanga, y que las letras pueden decir cosas más, ruido menos.

María Elena Walsh.

Contratapa del disco Juguemos en el mundo. Instrucciones para el disco oyente $\mathrm{n}^{\circ} 4$

\section{INTRODUCCIÓN}

Juguemos en el mundo de María Elena Walsh ${ }^{1}$ fue un espectáculo, ${ }^{2}$ dos discos, un libro, un film, ${ }^{3}$ y un producto artístico representativo de la cultura popular cosmopolita de la Argentina de finales de los sesenta. Se presentó el 4 de abril de 1968 en el teatro Regina de Buenos Aires con el título Juguemos en el mundo. Show para ejecutivos, bajo la dirección de María Herminia Avellaneda. ${ }^{4}$ Con este recital nace la María Elena ${ }^{5}$ para adultos. Sergio Pujol, en su biografía sobre Walsh, ${ }^{6}$ sostiene que incursionar en este terreno fue algo que ella afrontó con temor y con poca perspectiva de éxito. Sin embargo, este fue rotundo, prolongándose hasta 1971. Juguemos en el mundo se siguió recreando y difundiendo en los diversos formatos disponibles en el campo de la cultura de masas de aquel entonces.

1 María Elena Walsh (Argentina: 1930-2011). Los datos biográficos de María Elena se detallan con precisión en Como La Cigarra. Biografía de María Elena Walsh, publicada por Sergio Pujol en 2011. Ver Bibliografía. 2 La forma que le dio a este y otros espectáculos anteriores para niños se relaciona directamente con su paso por París en compañía de Leda Valladares. Juntas se ganaban la vida cantando a dúo (guitarra y voz) repertorio folklórico del noroeste argentino. Su estadía en Francia se prolongó por tres años, desde 1952 a 1955, en el transcurso de la cual obtuvieron contrato en Scandian Club, L'Ecluse, el Crazy Horse, la Fontaine de Quatre Saisons, Le Guitare, Teatro Marigny, Chez Pasdoc, etc.

3 Durante este período conocieron la modalidad del recital de Brassens, Montard, Brel y Ferre como una forma de comunicar con canciones, poesías y palabras.

4 Juguemos en el mundo: Doña Disparate y Bambuco. La ficha técnica se puede consultar en https://www. filmaffinity.com/es/film924836.html (último acceso 3/03/2021).

5 María Herminia Avellaneda. Cineasta y productora argentina de cine y televisión (1933-1997). En esa fecha era pareja de Ma. Elena Walsh. Doña Disparate y Bambuco fue su primer largometraje.

6 Con el nombre María Elena o Ma. Elena me refiero siempre a María Elena Walsh. 
Recordemos que solo en materia musical, en los sesenta asistimos al Boom del Folklore, el surgimiento del Movimiento Nuevo Cancionero, ${ }^{7}$ la reinvención del tango en la figura de Piazzolla, el naciente Rock Nacional, la publicación del cancionero tradicional para niños Canten Señores Cantores de Gainza y Graetzer, la Canción de Protesta, la Nueva Canción argentina ${ }^{8}$ y latinoamericana, ${ }^{9}$ entre otros. Juguemos en el mundo ocurre en el contexto del gobierno de facto de Juan Carlos Onganía (1966-1970), primera etapa de la dictadura cívico-militar autodenominada Revolución Argentina que, entre otras cosas, intentó disolver los partidos políticos y continuó con la proscripción del peronismo. ${ }^{10}$ En el aspecto económico, congeló la inflación junto con los salarios y devaluó la moneda nacional en un $40 \%$. Este gobierno tuvo en su haber acontecimientos dramáticos de repercusión nacional, de represión y censuras, incluidas las de tipo moral, vinculadas a todas las manifestaciones artísticas y sus hacedores. En el período comprendido entre 1969 y 1972 ocurrieron La noche de los bastones largos, el Cordobazo y Puebladas Argentinas como el Ocampazo y el Correntinazo, entre muchas otras.

María Elena trabaja con las voces de lo culto y lo popular representando con su música la densidad cultural de la sociedad en la que se inserta y a la que pone en diálogo con sus trayectos y experiencias. La obra de Walsh se puede insertar en la serie de episodios cosmopolitas de la cultura argentina, en el sentido en que lo enuncia Gonzalo Aguilar, aunque, como veremos, con algunas diferencias notorias respecto de los cosmopolitas de principios del siglo $\mathrm{xx}$.

Citando a Benedict Anderson, Aguilar sostiene: «El cosmopolitismo es un ideal al que se aspira, no una identidad completa que se asume»; y continúa: «El sujeto cosmopolita no posee una identidad fija y definida, sino que es una instancia móvil, operativa y disponible que se pro-

7 Pujol, S.: Como la Cigarra. capítulo VIII, p. 165 ss.

8 Al respecto se puede leer "Crisis del paradigma clásico, el movimiento nuevo cancionero" en Díaz, Claudio (2011) Variaciones sobre el "ser nacional». Una aproximación sociodiscursiva al "folklore argentino" Cap 5. 9 Liderado por Nacha Guevara, Jorge de la Vega, Marikena Monti, Jorge Schussheim, entre otros. 10 Se consideran a Atahualpa Yupanqui en Argentina y Violeta Parra en Chile como precursores. En la década del sesenta se destacan Víctor Jara en Chile, Víctor Heredia, Mercedes Sosa, Cesar Isella, y la misma María Elena Walsh entre los argentinos. Dentro de este movimiento se inserta la Nueva Trova Cubana. 
pone en un mismo gesto (de la actividad artística) redefinir las nociones de lo local, lo nacional, lo universal» (Aguilar, 2009:Io). Este cosmopolitismo puede pensarse como un ideal al que aspiran algunos sectores de una sociedad determinada de modo tal que opera, también, como un modo de pensar la cultura, en este caso la argentina, generalmente desde los grandes centros urbanos.

En ese marco, la de María Elena Walsh puede pensarse como una propuesta cosmopolita enunciada desde la Capital Federal, con la particularidad de que en ella convergen elementos de la cultura erudita y popular. En sus doce canciones conviven géneros musicales nacionales e internacionales como el tango, la zamba y el chamamé, junto con el son, el foxtrot, la habanera, el jazz, el vals y el bolero. En los textos de sus canciones se citan poemas de autores argentinos y latinoamericanos; se hace referencia a personas y lugares específicos del país y del mundo, y hay al menos tres canciones que provienen de distintos orígenes. Se encuentran poemas clásicos, entre ellos Cultivo una rosa blanca, del poeta cubano José Martí en las canciones: Para los demás y en Vals de los ejecutivos; el poema Setenta balcones y ninguna flor de Baldomero Fernández Moreno en la canción Los ejecutivos, y un verso del Himno Nacional Argentino en Zamba para Pepe. De entre las canciones citadas nos encontramos con Lobo está, en Diablo está; el clásico Arroz con leche, en el Vals del diccionario; las primeras notas del vals de Strauss Danubio azul, en la canción Manubrio azul; además de una paráfrasis de la melodía de Tangos viejos, en $\mathrm{El} 45$.

Lo nacional está presente no solo en algunos de los géneros musicales elegidos, también en las temáticas y en las personalidades de la cultura y la política que se mencionan: el periodista, pianista y fotógrafo José María (Pepe) Fernández ${ }^{11}$ (Zamba para Pepe); el surgimiento del peronismo y a su líder, Juan Domingo Perón ( $E l 45)$; lugares específicos de la capital (El Galeón, Plaza 25 de mayo); las situaciones que padecen los sectores populares más vulnerables de la sociedad: el abuelo preocu-

11 Onganía fue líder de la facción azul de las fuerzas armadas, los dos bandos: colorados y azules, tenían posturas diferentes respecto al peronismo. Los azules aceptaban un peronismo sin Perón, los colorados directamente querían erradicar el peronismo por considerarlo clasista y comunista. 
pado por su jubilación (Manubrio azul), la mujer de provincia que, desplazada, busca trabajo en la capital aunque no deja de sentirse desplazada, además de humillada (La Juana). En fin, situaciones concretas de los sectores vulnerables, a cuyas voces socialmente silenciadas y mediáticamente ignoradas María Elena le dedica su poesía, su voz y les entrega, y a la vez les debe, parte de su popularidad.

En esta trama intertextual, María Elena suele usar las melodías más populares, los poemas más conocidos, las frases y refranes más usuales. Ella no se dirige a un público elitista ni selecto, se comprende así la ironía del subtítulo Show para ejecutivos. En este punto nos preguntamos sobre el abordaje cosmopolita y el pastiche común a toda a la producción de María Elena en torno a la década del sesenta, tanto para público infantil como para adultos. Tomamos aquí la distinción que hace Pablo Alabarces:

No se trata de una mescolanza: se trata de una apuesta distribucionista de los bienes simbólicos, que evade la trampa tradicionalista y folklorista para, al mismo tiempo, organizarse en torno del respeto democrático por sus públicos, populares o no. (Alabarces, 2020:50) ${ }^{12}$

Alabarces encuentra en María Elena un ejemplo de aporte original dentro de las relaciones complejas que se dan entre las narrativas de la cultura de masas, las prácticas populares y la cultura culta:

La obra de Walsh es fundadora de una zona novedosa en la cultura argentina: la cultura de masas infantil. Su obra para niños se difundió también en buena parte de América Latina, en mucha mayor medida que su obra para adultos -valiosísima, pero de mucha menor difusión en nuestro continente-. El periplo que la condujo a esa producción, entre 1960 y 1968, es un ejemplo fantástico de lo que estamos discutiendo. (Alabarces, 2020:47)

12 Pepe Fernández se instala en París hacia 1960, fue un gran amigo de María Elena. 
Alabarces no avanza sobre la producción para adultos de María Elena sobre cuyos inicios nos ocupamos en este trabajo. Como veremos, consideramos que ella intenta mantener en sus canciones para adultos la misma estrategia poética. Si prestamos atención al título del espectáculo, María Elena interpela a este nuevo público desde su propia trayectoria artística: les propone que ellos también pueden jugar en un espacio que alcanza una escala global.

En el siguiente apartado nos enfocaremos en dos canciones del primer álbum: Manubrio azul y $\mathrm{El} 45 \cdot{ }^{13}$ Son dos de las tres canciones que presentan un alto grado de intertextualidad. No solo citan otros textos sino también otros tipos de lenguajes artísticos (música, cine) de modos diversos. Allí intentaremos comprender cómo estas canciones proponen una variante cosmopolita de representar musicalmente a la Argentina de finales de los sesenta.

\section{Acerca del disco}

Enumeramos aquí algunos aspectos relevantes que se encuentran en el disco que lleva el nombre del espectáculo Juguemos en el mundo, ya sin el subtítulo del espectáculo teatral. ${ }^{14} \mathrm{El}$ disco contiene en su contratapa una serie de Instrucciones para el disco-oyente. Entre los seis puntos, vemos que se especifica que «se trata de canciones para adultos» $\left(\mathrm{n}^{\circ} 2\right)$, que «el disco-oyente debiera tener algo de cultura general» $\left(\mathrm{n}^{\circ} 3\right)$, y «estar un poco chiflado por valorar la música popular» $\left(\mathrm{n}^{\circ} 4\right)$ entre otras. ${ }^{15}$

El disco, que salió con posterioridad al espectáculo, pero durante el mismo año debido a su enorme éxito, consta de doce canciones. Las mismas formaron parte del show en vivo, de las que se especifica el género solo en el disco. La lista de temas incluye: I. Para los demás (Son), 2.

13 La cursiva es mía.

14 Las canciones que en este disco citan otras melodías son tres: Manubrio azul, El 45 y Diablo está? La última no se aborda solo por límites de espacio. De todos modos, las dos primeras sirven para dar cuenta de los disímiles modos de representación hipertextual y cosmopolita de María Elena.

15 Se puede ver la tapa del disco en https://www.cancioneros.com/nd/1889/55/juguemos-en-el-mundomaria-elena-walsh (Último acceso 9/02/2021). 
Vals del diccionario (Vals), 3. Zamba para Pepe (Zamba), 4. Los ejecutivos (Vals), 5. El 45 (Tango), 6. Miranda y Mirón (Foxtrot), 7. Diablo estás? (Marcha), 8. Serenata para la tierra de uno (Habanera), 9. Manubrio azul (Vals), io. La Juana (Chamamé), II. La ciudad de Brujas (Bolero), I2. Las estatuas (Zamba). La duración de las canciones oscila entre los 2 y los 4 minutos, siendo la más extensa la canción Los ejecutivos ${ }^{16}$ que supera los 4 minutos. La interpretación está a cargo de María Elena Walsh (voz), Oscar Cardozo Ocampo en piano y arreglos de orquesta. ${ }^{17}$

\section{Dos canciones del álbum}

\section{1 - Manubrio azul}

Manubrio $A z u l^{18}$ nos cuenta sobre un abuelo, preocupado por su jubilación y abstraído por sus recuerdos. El paseo por el parque, la nostalgia y los recuerdos que se disparan a partir del color azul de una flor, en épocas de primavera, provocan que el abuelo desplace la preocupa-

16 Se transcriben aquí las "Instrucciones para el disco-oyente»: " $1^{\circ}$ - Téngase en cuenta que en algunos lugares de América todavía existe la costumbre de dar serenatas, y que todo este disco es quizás una serenata, (no confundir con sanata) un poco antigua, bastante melancólica y a ratos mufada. Y qué?, $2^{\circ}-$ Aunque la autora ha grabado anteriormente canciones para niños, estas son para grandes. De todas maneras es preferible mantenerlas al alcance de los niños, ya que no contienen elementos nocivos, y los discos se deterioran con el forcejeo, como atestigua el famoso sabio Discóbolo. $3^{\circ}$ - Es necesario aclarar que Brujas no es la residencia de señoras montadas en escobas, sino una ciudad del reino de Bélgica? No, no es necesario aclararlo, puesto que se descuenta que el estimado disco-oyente es culto. $4^{\circ}$ - Este disco está dedicado a los chiflados que suponen que la música popular puede no ser necesariamente pachanga, y que las letras pueden decir cosas más, ruido menos. $5^{\circ}$ - Este disco también puede serle útil a los que todavía extrañan leer en el tranvía y a los adolescentes inconformistas que odian las flores de plástico. $6^{\circ}$ - Es evidente que podemos jugar en el mundo, o cantar en el mundo mientras el Diablo no está. También es evidente que cuanto más cantamos o jugamos, mejor le haremos la guerra. María Elena Walsh".

17 Los Ejecutivos es analizada en profundidad por Mirta M. González Barroso en "María Elena Walsh en la canción argentina de los sesentan p. 85 ss. También por Sergio Pujol en Canciones argentinas (1910-2010). p. 204 ss.

18 Oscar Cardozo Ocampo (Bs. As. 1942-Resistencia 2001). Fue un pianista, compositor, arreglador y director de orquesta argentino. Miembro de una familia de músicos (su padre fue el compositor uruguayo Mauricio Cardozo Ocampo), incursionó en la música para cine, televisión y teatro; hizo arreglos para renombrados cantantes argentinos y paraguayos, entre ellos Eduardo Falú, Mercedes Sosa, Ariel Ramírez. Su búsqueda como compositor lo llevó a proponer proyecciones nuevas a tradicionales ritmos folklóricos sudamericanos. 
ción inicial (la jubilación) y la reemplace por el deseo de mantener su vida en primavera, esperando que esta, a diferencia de la jubilación, no se marchite jamás.

\section{Manubrio Azul}

$\begin{array}{lll}\text { Un abuelo, un abuelo muy viejito } & 11 & \mathrm{~A} \\ \text { Por el parque se pasea con bastón. } & 11+1 & \mathrm{~B} \\ \text { No le importa si llegó la primavera, } & 12 & \mathrm{C} \\ \text { Sólo espera cobrar la jubilación. } & 11+1 & \mathrm{~B} \\ \text { De repente, de repente se detiene } & 12 & \mathrm{D} \\ \text { Y algo busca que se le perdió. } & 9+1 & \mathrm{~B} \\ \text { M ira al suelo, mira al cielo } & 8 & \mathrm{E} \\ \text { Y mira alrededor. } & 6+1 & \mathrm{~B}\end{array}$

Por dónde andará -manubrio azul- 9+1 A

Color de un triciclo del ayer. $\quad 9+1 \quad$ B

Un juguete de pura nostalgia $10 \quad \mathrm{C}$

Que a su infancia lo lleve otra vez, $9+1 \quad$ B

Que se ponga a rodar para atrás $9+1 \quad$ D

Hasta mil novecientos tres. $\quad 9+1 \quad B$

Por dónde andará -manubrio azulRelámpago de felicidad.

El abuelo se trepa a una hamaca,

Se desliza por el tobogán

Y cabalgando en el sube y baja

A su antigua niñez se va.

Por dónde andará -manubrio azul-

Amor que el olvido le robó

El azul de su viejo triciclo

De repente lo halló en una flor,

Una flor que esperaba en el tiempo

Y sólo por él florece hoy.

Un abuelo, un abuelo muy viejito

Por el parque se pasea con bastón.

Sólo espera recobrar la primavera,

No le importa nada la jubilación.

De repente, de repente se detiene

A ponerse la flor en el ojal.

Ese algo que esperaba

Figura I: Texto y métrica

No se marchitará.

de la canción Manubrio azul

Compuso la Banda sonora de las películas La Patagonia Rebelde, Pasajeros de una pesadilla o No habrá más penas ni olvido, entre otras.

En el primer enlace se puede escuchar la canción cantada por María Elena Walsh, en el marco de la película Cantemos por el mundo grabada en 1971. En el segundo enlace se accede a la película completa.

https://www.ciudad.com.ar/video/maria-elena-walsh-canta-manubrio-azul-pelicula-juguemos-mundo-1971_15796 (último acceso 9/03/2021) https://www.youtube.com/watch?v=V9V6I3D-7NI (último acceso 9/03/2021) 


\subsubsection{Sobre la poesía}

Consta de cinco estrofas, agrupadas en dos estructuras diferentes. Las estrofas i y 5 cuentan con ocho versos de metro variable, en el que predominan los versos dodecasílabos, además de rima y acentuación final aguda en los versos pares. Las estrofas 2, 3 y 4 poseen 6 versos, de los cuales los primeros 5 son decasílabos y el último eneasílabo. Esta estructura también rima en los versos pares y predomina en ella la acentuación final aguda.

\subsubsection{Sobre la música}

Género: vals solo en la sección B (ver gráfico I) Jazz en la sección A. Forma de arco de cinco estrofas organizadas, temática y comparativamente, de la siguiente manera: A-B-B-B-A.

Armonía: Tonalidad Si mayor. En los arreglos de Oscar Cardozo Ocampo abundan los cromatismos en líneas melódicas distribuidas en toda la textura, estos cromatismos afectan a las funciones armónicas básicas generando tensiones e intercambio modal.

$\sim$ Metro variable: seis octavos con ritmo de jazz en la sección A (primera y quinta estrofa), y tres cuartos con ritmo de vals en la sección

B, estrofas 2,3 y $4 \cdot{ }^{19}$

Timbres: voz, percusión y cuerdas.

\begin{tabular}{|c|c|c|c|c|c|c|c|c|c|c|c|c|c|c|c|c|c|c|}
\hline \multicolumn{19}{|c|}{ Walsh, María Elena "Manubrio azul" } \\
\hline Intro & \multicolumn{4}{|c|}{ A (jazz) } & \multirow{2}{*}{\multicolumn{3}{|c|}{$\begin{array}{l}\text { B (vals) } \\
C\end{array}$}} & \multirow{2}{*}{\multicolumn{3}{|c|}{\begin{tabular}{|l|} 
B (vals) \\
C
\end{tabular}}} & \multirow{2}{*}{\multicolumn{3}{|c|}{\begin{tabular}{|l|} 
B (vals) \\
C \\
\end{tabular}}} & \multicolumn{4}{|c|}{ A (jazz) } & \multirow{2}{*}{\begin{tabular}{|l|} 
Coda \\
$a^{\prime}$
\end{tabular}} \\
\hline & \multicolumn{2}{|l|}{$a$} & \multicolumn{2}{|c|}{$\mathrm{b}$} & & & & & & & & & & a & & $\mathrm{b}^{\prime}$ & & \\
\hline & $a$ & $a$ & $\bar{b}$ & $\bar{a}$ & $c$ & $d$ & $e$ & $c$ & $d$ & $e$ & $c$ & $d$ & $\bar{e}$ & $\bar{a}$ & $a$ & $\bar{b}$ & $a^{\prime \prime}$ & \\
\hline 4 & 8 & 8 & 8 & 8 & 8 & 8 & 10 & 8 & 8 & 10 & 8 & 8 & 10 & 8 & 8 & 8 & 8 & \\
\hline
\end{tabular}

Imagen 2: Estructura y forma de Manubrio azul ${ }^{20}$

19 Martin Liut, a través de un comentario personal, aporta que se podría pensar este vals como "jazzeade» o "Jazz waltz" dentro de la construcción genérica del jazz. (29/04/2021).

20 Fila 2: 1er nivel de articulación formal, incluye las cinco estrofas poéticas más introducción y coda. Las letras A y B indican dos secciones diferentes desde el punto de vista melódico. Fila 3: 2do nivel de articulación y Coda. Fila 4: 3er nivel de articulación, conformada por períodos de 8 y de 10 compases. Fila 5: indica la cantidad de compases que abarca cada unidad formal de 3er nivel. 


\subsubsection{Un mundo de asociaciones}

Usar ritmo de vals en una canción que habla de un abuelo que recuerda su infancia durante la primera década del siglo xx no es ninguna novedad, se podría decir que es apropiado. Pero el vals que asume el texto de los recuerdos se combina con jazz en las estrofas que remiten al tiempo presente. La secuencia cronológica va del presente al pasado y vuelve al presente acompañando este proceso con los géneros musicales utilizados, cambios de metro, estructura poética y diseño melódico.

La frase Manubrio azul se da en ritmo de vals, con el mismo diseńo melódico del más popular de los valses de Strauss: A orillas del Danubio $A z u l$. A esto hay que sumarle que el sintagma Manubrio azul no es original de María Elena, sino que fue extraído de un chiste del personaje de Catita, representado por Niní Marshall, ${ }^{21}$ en la película Porteña de Corazón (1948). ${ }^{22}$ Recordemos que Catita basaba parte de su humor en confundir continuamente nombres de autores, obras o palabras. María Elena recupera para esta canción esa confusión de Catita respecto del título del vals de Johann Strauss para imaginarlo como ese manubrio azul de un triciclo. La trama se completa con la cita musical de la melodía del vals (8 compases con identidad melódica y rítmica), además de una cita de una película que a la vez parodia el vals tradicional. ${ }^{23}$

Se confirma así la tesis de Pablo Alabarces que afirma que María Elena es un claro ejemplo de las relaciones complejas que se dan entre las prácticas populares y la cultura culta. Esto se manifiesta en su música, pero también en su narrativa a lo largo de toda su producción. La misma María Elena da cuenta de esto si repasamos las instrucciones para el disco Oyente. Asimismo, recordamos un fragmento de un conocido ensayo de Borges: El escritor argentino y la tradición (195I) que ilustra perfectamente

21 María Esther Traverso (Bs. As. 1903-1996) Nombre artístico: Niní Marshall. Fue actriz, guionista y comediante argentina, sus comedias más populares fueron las que se desarrollaron en la década que va desde fines del 30 a fines del 40.

22 El dato fue aportado por Pujol (2011: 179-180) la escena se puede ver en el siguiente sitio web: https:// www.youtube.com/watch?v=kc_GEmFVQ2s, desde 1:03:50 (último acceso 15/03/2021).

23 Transcribo aquí una definición breve de lo que se entiende por Parodia en música: Una obra que, con intención humorística o satírica lleva a cabo un uso distorsionado o exagerado de elementos de alguna otra obra o tipo de obras. Extraído de Diccionario Harvard de la Música, p. 778 (ver bibliografía). 
la estética cosmopolita de una época que, por extensión, incluye a nuestra autora: «Creo que los argentinos, los sudamericanos en general, estamos en una situación análoga; podemos manejar todos los temas europeos, manejarlos sin supersticiones, con una irreverencia que puede tener, y ya tiene, consecuencias afortunadas» (Aguilar, 2009:I2). ${ }^{24}$ Nos preguntamos sobre el lugar de lo local/regional/nacional que se representa en la canción Manubrio azul. El protagonista de la historia es un abuelo en una situación común a los adultos mayores: la preocupación por la jubilación que nunca alcanza. Con la frase «solo espera cobrar la jubilación» es evidente que este abuelo no tiene privilegios, es uno más de los que cobran la mínima por lo que asumimos que no puede ser extranjero. De todas maneras, una connotación fuerte que nos baja a tierra nacional es la cita literal y musical del Manubrio azul de Nini Marshall, personaje fuertemente asociado a la comedia argentina en la década del 40. Esta canción funciona como un texto social que describe la vulnerabilidad de un adulto mayor en el contexto de la crisis económica provocada por la dictadura.

\subsection{El $45^{25}$}

En una entrevista que Rosana Kreimer le realizó a María Elena en el programa El Sonajero (1989), ${ }^{26}$ refiriéndose al uso que hace María Elena de Panfletos contrabandeados en canciones en los que defiende los derechos de la mujer, ella menciona la canción $E l$ 45:

$\mathrm{Y}$ en uno de los pocos tangos que compuse hay un hecho modestamente insólito que es un tango en que una mujer le habla a otra y le dice «te acordás hermana», es una parodia del tango Tiempos Viejos pero, claro, en nuestro tango, en general, el que lleva la voz cantante

24 Citado por Gonzalo Aguilar (2009) p. 12. Del texto de Borges «El escritor argentino y la tradición», 1951. 25 El estribillo se diferencia de la estrofa por estar escrito en cursiva. Link para acceder al audio de la canción:https://www.youtube.com/watch?v=msc3HOyM82g (último acceso 10/03/21).

26 El programa se transmitía por canal 9. La frase transcripta se puede ver desde el minuto 4:11 en el siguiente enlace https://www.youtube.com/watch?v=2PUVnzMpkAc\&feature=youtu.be (ultimo acceso 
es el muchacho. Y parece que las mujeres no tuviéramos nostalgia de... de nuestras mocedades. Creo que también el tema está implícito, es un punto de vista frente a la sociedad, un punto de vista que a veces es doméstico, es cotidiano, y por eso también puede ser víctima de algún ninguneo como suele suceder con las actividades de las mujeres que siempre resultan desvalorizadas.

\section{El 45}

Te acordás, hermana, qué tiempos aquellos, la vida nos daba la misma lección. $12 \quad$ A

En la primavera del cuarenta y cinco

$11+1 \quad B$

tenías quince años, lo mismo que yo.

Te acordás, hermana, de aquellos cadetes,

el primer bolero y el té en El Galeón

cuando los domingos la lluvia traía

la voz de Bing Crosby y un verso de amor.

Te acordás de la Plaza de Mayo,

cuando el que te dije salía al balcón.

Tanto cambió todo que el sol de la infancia

de golpe y porrazo se nos alunó.

Te acordás, hermana, qué tiempos de seca, cuando un pobre peso daba el estirón $y$ al pagarnos toda una edad de rabonas valia más vida que un millón de hoy.

Te acordás, hermana, que desde muy lejos un olor a espanto nos enloqueció.

Era de Hiroshima, donde tantas chicas

tenían quince años como vos y yo.

Te acordás que más tarde la vida vino en tacos altos y nos separó.

Ya no compartimos el mismo tranvia,

La canción también se mete de lleno en el gran dilema de la política nacional de la época. Aunque en I968 se había derogado el decreto 4I6I que prohibía la mención del nombre de Juan Domingo Perón, además de nombres y símbolos asociados, Onganía todavía sostenía una activa política de represión y censura, que también involucraba al campo artís- 
tico. ${ }^{27}$ La canción habla de Perón y del peronismo, junto con la cuestión de género, sin necesidad de la mención directa. El título de la canción podría ser ambiguo, ¿se trata de un número?, ¿una línea de colectivo? El tercer verso de la primera estrofa lo clarifica, ya que nos ubica concretamente en la primavera 1945, lo que no deja lugar a dudas sobre el momento histórico que describe. Luego, el estribillo hace una mención a Perón con una frase de uso coloquial: «Te acordás de la Plaza de Mayo cuando "el que te dije"28 salía al balcón».

La articulación entre política nacional y empoderamiento femenino se completa con una trama de menciones de otros acontecimientos y personalidades asociados al año 1945: la tragedia de Hiroshima, sucedida el 6 de agosto de 1945, y Bing Crosby, actor y cantante de jazz, blues y pop que alcanzó los primeros puestos en venta de discos entre 1930 y $1954 .{ }^{29}$ Todo esto en el mismo paquete de una canción, unidos por impacto del año 1945 en la mentalidad de dos mujeres adolescentes.

\subsubsection{Sobre la poesía}

La poesía consta de seis estrofas de cuatro versos con rima asonante en los versos pares, libre en los impares. Acentuación final aguda en los versos pares (oxítono) y grave en los impares (paroxítono). No hay diferencias en rima, métrica mi acentuación entre estrofas y estribillos.

27 Para más información se puede consultar en varios sitios, entre ellos: https://www.pagina12.com.ar/225593-el-discurso-de-peron-del-17-de-octubre-de-1945 (consultado 17/02/2021). El decreto $n^{\circ} 4161$ se puede leer en

http://servicios2.abc.gov.ar/docentes/efemerides/24marzo/htmls/decadas/descarga/decreto.pdf (último acceso 9/03/2021)

28 El entrecomillado es mío. Recordemos que el 45 fue el año fundacional del Peronismo como movimiento político a partir de los acontecimientos ocurridos el 17 de octubre de ese año.

29 En 1944 gana el premio de la Academia por su interpretación de O 'Malley en Going My Way de Leo McCarey. Al finalizar la segunda guerra mundial una encuesta lo declara la persona que más había hecho para levantar la moral de los soldados durante la guerra. Cfr. https://bingcrosby.com/bing-bio (ultimo acceso 12/03/2021).

96 | Cosmopolitismo y nación: Juguemos en el mundo de María Elena Walsh [Verónica P. Pittau] 


\subsubsection{Sobre la música}

$\sim$ Género: tango

$\sim$ Forma binaria: alterna estrofa A - estribillo B. La estrofa musical abarca dos estrofas poéticas, en cambio el estribillo solo una. Damos cuenta del estribillo solo por la recurrencia temática musical, no por repetición de texto.

Armonía: Tonalidad Do Mayor. Se utilizan dominantes secundarias e intercambio modal producido por efecto del desplazamiento de líneas melódicas cromáticas.

Melodía: La melodía está a cargo de la voz. En la mayoría de las frases, todas de cuatro compases, predomina un diseño de arco ascendente, siendo la nota más grave un Sol 3 y su nota más aguda Sib 5 . El clímax melódico se da en una nota extraña a la escala, Sib como apoyatura de La, esto sucede solo en las frases c y c', finales de estrofa y estribillo respectivamente.

Metro fijo: cuatro cuartos.

Timbre: piano e instrumentos de orquesta. La introducción está a cargo del piano.

\begin{tabular}{|c|c|c|c|c|c|c|c|c|c|}
\hline \multicolumn{10}{|c|}{ Walsh, Maria Elena "El 45" } \\
\hline \multirow[t]{2}{*}{ Intro } & \multicolumn{4}{|c|}{ Estrofa 1} & \multirow{2}{*}{\multicolumn{2}{|c|}{$\frac{\text { Estribillo } 1}{\mathrm{~B}}$}} & \multicolumn{2}{|c|}{ Estrofa 2} & Estribillo 2 \\
\hline & \multicolumn{2}{|c|}{$\bar{A}$} & \multicolumn{2}{|c|}{$\overline{A^{\prime}}$} & & & \multirow[t]{2}{*}{$\bar{A}$} & \multirow[t]{2}{*}{$\bar{A}^{\prime}$} & $\overline{B^{\prime}}$ \\
\hline \multirow[b]{2}{*}{4} & $\bar{a}$ & b & $\mathrm{a}^{\prime}$ & c & d & $\mathrm{c}^{\prime}$ & & & \\
\hline & 4 & 4 & 4 & 4 & 4 & 4 & idem & idem & idem \\
\hline
\end{tabular}

Figura 4: Estructura y forma de $\mathrm{El} 45 .^{30}$

30 Fila 2: 1er nivel de articulación formal, incluye las seis estrofas poéticas agrupadas en estrofa y estribillo. Se añaden 4 compases de introducción. Las letras A y B indican dos secciones temáticas diferentes desde el punto de vista melódico. A y $A^{\prime}$ tienen solo un $50 \%$ de similitud melódica, esto mismo sucede entre $A^{\prime}$ y $B$ por lo que el criterio para colocar A en una y $B$ en otra fue su pertenencia a estrofa o al estribillo respectivamente. Fila 3: 2do nivel de articulación, se aprecian aquí frases de cuatro compases, las letras reflejan su igualdad, similitud o diferencia melódica. Fila 4. Solo se indican aquí cantidad de compases. Ambos finales de estribillos son iguales, articulando (en B) y finalizando (en B') con un calderón. 


\subsubsection{De la Plaza de Mayo a Hiroshima}

Nos dice María Elena que $E l 45$ es una parodia de Tiempos viejos. ${ }^{31}$ Aportaríamos que, además y salvando las distancias, tenemos aquí un caso de paráfrasis musical. ${ }^{32} \mathrm{Si}$ bien en $E l$ 45 la estructura no coincide en su totalidad con Tiempos viejos. Este último posee un estribillo formado por 8 versos y el tango de María Elena solo tiene 4; la melodía de $\mathrm{El}_{45}$ posee un registro más amplio y está en tonalidad mayor cuando Tangos viejos está en tonalidad menor-, los versos de ambas canciones son de doce sílabas métricas y la duración de frases de 4 compases. ${ }^{33}$ Además, es clara la referencia de la frase "Te acordás hermana» de $E l 45$ a «Te acordás hermano» de Tiempos viejos. La frase remite a los I5 años de las mujeres y a los 25 años de los hombres. Esta referencia nos invita a pensar si $\mathrm{El}_{45}$ no es un metatexto de Tangos viejos, teniendo en cuenta que, según la teoría literaria de Gerard Genette, la metatextualidad es por excelencia, la relación crítica entre dos textos. ${ }^{34}$ No hace falta explicar por qué $E l 45$ se puede considerar una lectura crítica del tango original, lo explica su autora de forma contundente en la entrevista que citamos previamente. María Elena es una feminista de avanzada. En este tango, al darle la palabra a dos mujeres, tomándola desde un tango protagonizado por un par de hombres, posiciona las voces femeninas en lugar de las masculinas. Es un acto concreto de igualación de derechos, derecho a la expresión, a la memoria y al reconocimiento social.

Además, en la misma canción se conjugan el Perón de la Plaza de Mayo, lamentos por penurias económicas, el amor, las salidas a tomar el té en El Galeón, la música de Bing Crosby, y la tragedia de Hiroshima. Lo microsocial junto con los acontecimientos políticos nacionales y glo-

31 Tiempos viejos fue compuesta en 1926 por F. Canaro y M. Romero. Se puede escuchar una versión de Carlos Gardel en https://www.todotango.com/musica/tema/581/Tiempos-viejos/ (último acceso 12/03/2021). 32 Paráfrasis: El proceso mediante el cual un compositor cita una melodía con gran fidelidad, pero la elabora libremente según va avanzando (Spark, 1963) citado en Diccionario Harvard de la Música, p. 776 (ver bibliografía).

33 Si fuera posible continuar este trabajo sería provechoso realizar una transcripción de ambas melodías a los efectos de comparar sus diseños.

34 Genette G. Palimpsestos. La literatura en segundo grado. p. 13 (ver bibliografía). 
bales impresionan al mismo nivel y con la misma fuerza en las mentalidades de estas jóvenes quinceañeras.

Nos encontramos con una canción impregnada de cosmopolitismo, en la que se logra establecer una dialéctica entre lo local y lo universal que - parafraseando a Gonzalo Aguilar - permite vincular la modernidad con el territorio sin caer en una asociación automática y falsa entre lo local como territorio propio y lo universal como modernidad ajena (Aguilar: 2008:17).

\section{Conclusión}

Es evidente que podemos jugar en el mundo, o cantar en el mundo mientras el Diablo no está. También es evidente que cuanto más cantamos o jugamos, mejor le haremos la guerra.

María Elena Walsh, Contratapa del disco Juguemos en el mundo. Instrucciones para el disco oyente $n^{\circ} 6$

Al comenzar este trabajo nos preguntábamos el por qué, el para qué y el cómo del uso de tan variadas referencias en las canciones de María Elena. Creemos que de esta manera su música y su poesía supera sus propios límites. Desde Buenos Aires postula que su lugar es el mundo. Cantemos en el mundo es cosmopolita en el sentido positivo del término: ${ }^{35}$ extiende fronteras, difumina límites. Mediante estas conexiones se trae al escenario a la canción como producto estético en el que convergen pasado y futuro, las artes en todas sus expresiones, se reúne lo popular y lo académico, lo local y lo internacional, los recuerdos, los sueños y los deseos, pero sobre todo se hacen eco las voces que denuncian y que reclaman.

35 Gonzalo Aguilar, dentro de la introducción, en el subtítulo "El retorno a casa» menciona las connotaciones negativas del término "cosmopolita" (asociado a elitismo, deslealtad y traición) en las décadas del 20-30 y su revalorización a partir de las discusiones entre Habermas y Foucault sobre Kant y la llustración (2008:15 ss). 
Mirta González Barroso habla de representaciones de identidad e interculturalidad en el cancionero infantil de Ma. Elena Walsh, ${ }^{36}$ con este trabajo notamos que estos rasgos no solo se mantienen sino que se profundizan tanto en la poesía como en la música de sus canciones para adultos.

Hemos hablado de dos canciones: una que podría considerarse un tango feminista, cargada de referencias a un año significativo para la historia política y social de Argentina sin dejar de mencionar el contexto internacional; la otra, una canción que, a primera vista y en cuanto a referencias, podría considerarse sin bandera, pero que describe una situación cotidiana para los adultos mayores argentinos. Ambas utilizan diferentes modos de representar la nación. Sin embargo, las canciones seleccionadas no fueron populares a diferencia de otras canciones del álbum, como Serenata para la tierra de uno, Miranda y Mirón y Los ejecutivos que fueron más trashumantes ${ }^{37}$ con posterioridad al show y al disco.

En una época asfixiante ${ }^{38}$ María Elena gesta un estilo único que la distingue de las demás propuestas musicales argentinas de la década. Sus canciones interpelan a la memoria y se vuelven significativas para quienes las escuchan adquiriendo contextos reales locales y universales, sin dejar de lado el aspecto emocional. En este sentido es importante mencionar que ninguna de las canciones de este álbum adhiere al tópico del amor romántico, lo que durante la segunda mitad de la década del sesenta se vuelve cada vez más frecuente, sobre todo en «la nueva canción» argentina. María Elena Walsh no firmó el manifiesto del Nuevo Cancionero ${ }^{39}$ de 1963, pero bien podría haberlo hecho ya que este disco, como tam-

36 Gonzalez Barroso, Mirta «Identidad e interculturalidad en el cancionero infantil propuesto por la poetisa María Elena Walsh (1930-2011)" en Dedica, Revista de Educaçao e Humanidades n4. Marzo de 2013 p 199-219.

37 El término trashumante a propósito de las canciones fue tomado de Gilbert y Liut (2019) Las mil y una vidas de las canciones.

38 "Cantemos en el mundo" se desarrolla en tiempos de la "Revolución Argentina" (1966-1973). Así se autodenominaba la dictadura militar que derrocó a Illia y cuyo poder estuvo a cargo de tres dictadores sucesivos, el primero de ellos J. C. Onganía. En este período se produjo la primera y más importante "fuga de cerebros" de Argentina.

39 El Manifiesto del Nuevo Cancionero se puede consultar en:

https://web.archive.org/web/20171127015342/http://www.tejadagomez.com.ar/adhesiones/manifiesto.html (ultimo acceso 12/03/2021). 
bién otros anteriores del repertorio de la infancia, ${ }^{40}$ se hacen cargo de varios de sus postulados, entre ellos la integración de la música popular en las expresiones regionales del país; la aplicación de la conciencia nacional en nuevas y mejores obras que lo expresen; la participación de la música en las demás artes populares, el cine, la danza el teatro etc.; el rechazo el regionalismo cerrado y la búsqueda de expresar al país en su amplia gama de formas musicales, entre muchos otros.

Vemos así que el efecto que el cosmopolitismo tiene en María Elena no solo se hace sentir sobre lo universal, sino también sobre lo local. Lo que afirma Gonzalo Aguilar se comprueba en la obra de Walsh «cosmopolitismo y localismo no se oponen, más bien lo que hacen los cosmopolitas es investigar las distorsiones que con la modernidad se producen en la idea de localidad» (Aguilar, 2009:15).

Refiriéndose a la literatura de Rubén Darío, Jorge Luis Borges, Victoria Ocampo, Oliverio Girondo y Leopoldo Torre Nilsson, Gonzalo Aguilar dice:

La censura en el terreno de la moral y de las imágenes, la religión con su carácter de interdicción, el arte como una práctica de una elite letrada que educa (en sus variantes de izquierda o de derecha), la transgresión en el terreno de las prácticas sexuales, el viaje como modo de trasladar ideas e imágenes: todo eso puede existir hoy en día pero de un modo muy diferente a como lo hizo a lo largo del siglo Xx. Sin embargo, vistos desde la actualidad, hay dos aspectos de la experiencia cosmopolita que me resultan curiosos e intrigantes: la vigencia de sus obras (sobre todo si se las compara con las que se movieron dentro de la literatura social o que tuvieron un carácter nacionalista) y la politicidad que adquirieron sus textos con el correr de los años. (Aguilar, 2009:3I)

Se puede poner en diálogo a este grupo de escritores desde la poética cosmopolita, aunque también masiva y popular, de María Elena Walsh ya que muchas de sus canciones con el paso del tiempo se volvie-

40 Un enfoque similar al de este trabajo pero aplicado al repertorio infantil de María Elena se puede leer en: Pittau, V. «Expresión y transgresión en 'Canciones Para Mirar’ de Ma. Elena Walsh (en bibliografía). 
ron sinónimos de Patria, valga La cigarra y El twist del mono liso ${ }^{41}$ como clásicos ejemplos. Además, lo hace combinando elementos de la cultura popular y mediática lo que confirma un tipo de cosmopolitismo democrático y no elitista.

\section{Discografía}

WALSH, MARÍA ELENA (1968). Juguemos en el mundo. [disco de vinilo] Buenos Aires: CBS, 8830.

\section{REFERENCIAS BIBLIOGRÁFICAS}

AGUILAR, GONZALO (2009). Episodios cosmopolitas en la cultura argentina, Buenos Aires: Santiago Arcos Ed.

ALABARCes, pablo (2020). Pospopulares. Las culturas populares después de la hibridación, Bielefield: Bielefield University Press/CALAS.

DÍAZ, CLAUDIO (2011). Variaciones sobre el "ser nacional». Una aproximación sociodiscursiva al "folklore argentino", Buenos Aires: Ediciones recovecos. GENETTE, GÉrARD (1989). Palimpsestos. La literatura en segundo grado, Madrid: Taurus.

GILBERT, ABEL Y LIUT, MARTín (comp.) (2019). Las mil y una vidas de las canciones, 1ra Ed., Ciudad Autónoma de Buenos Aires: Gourmet Musical. pujol, sergio (2011). Como la Cigarra. Biografía de María Elena Wals, $1^{\circ}$ Ed., Buenos Aires: Emecé.

PUjOL, SERGIO (2010). Canciones argentinas (1910-2010), Buenos Aires: Emecé RANDEL, DON MiChaEl (Ed.) (1997). Diccionario Harvard de la Música, Madrid: Alianza Editorial [1986].

41 El Twist del mono Liso salió por primera vez en el disco Doña Disparate y Bambuco (1962), La Cigarra en 1973, ambas canciones -entre otras canciones y cuentos infantiles de Ma. Elena- estuvieron en la lista negra en la época del Proceso de Reorganización Nacional (como se autodenominó la dictadura militar que gobernó el país entre 1976 y 1983). 


\section{Sitios WeB}

GONZÁLEZ BARROSO, MIRTA MARCELA (2013). Identidad e interculturalidad en el cancionero infantil propuesto por la poetisa María Elena Walsh (1930-2011), Dedica, revista de Educaçao e Humanidades, n 4. Marzo de 2013 pp.199-

219. https://dialnet.unirioja.es/servlet/articulo?codigo $=4252441$ [consultado: 8/8/19]

GONZÁLEZ BARRoso, MiRTA MARCELA (2015). María Elena Walsh en la canción argentina de los sesenta, Cuadernos de Etnomusicología. № 6. https://www. researchgate.net/publication/325113579_Maria_Elena_Walsh_en_la_cancion_ argentina_delos_60 [consultado: 15/10/20] https://www.sibetrans.com/etno/ public/docs/7-maria-elena-walsh-en-la-cancion-argentina-de-los-sesentamirta-gonzalez.pdf [consultado: 10/03/21]

PITTAU, VERóNiCA (2019). Expresión y transgresión en "Canciones para Mirar» de María Elena Walsh, Actas de músicos en congreso 2019, Santa Fe, Universidad Nacional del Litoral, https://www.academia.edu/43890721/Canciones_para_ Mirar_de_Mar\%C3\%ADa_Elena_Walsh [consultado: 15/03/2021]

\section{Música}

JUGUEMOS EN EL MUNDO (DISCO I): https://www.youtube.com/watch?v=ipHMg8 B1yk4\&list=OLAK5uy_nGyXWMNHAHDYeo19B9rwNyErB2aFrhWFA [consultado: 17/02/2021]

TIEMPOS VIEJOS: https://www.todotango.com/musica/tema/581/Tiempos-viejos/ [consultado: 18/02/2021]

\section{Artí́culos periodísticos}

https://www.infobae.com/cultura/2018/12/29/juguemos-en-el-mundo-elespectaculo-con-el-que-hace-50-anos-maria-elena-walsh-conquisto-a-losadultos/ [consultado: 9/03/2021]

https://cablearmstrong.com.ar/2018/12/29/juguemos-en-el-mundo-elespectaculo-con-el-que-hace-50-anos-maria-elena-walsh-conquisto-a-losadultos/ [consultado: 17/02/2021]

ENTREVISTA DE «EL SONAJERO» A MARÍA ELENA WALSH: https://www.youtube. $\mathrm{com} /$ watch?v=2PUVnzMpkAc\&feature =youtu.be [consultado: 18/02/2021] 


\section{TeXTo DE LAS CANCIONES DEL DisCo I}

https://www.cancioneros.com/nd/1889/55/juguemos-en-el-mundo-maria-elenawalsh [consultado: 17/02/2021]

\section{MANifiesto Del NUEvo CANCIONERO}

https://web.archive.org/web/20171127015342/http://www.tejadagomez.com.ar/ adhesiones/manifiesto.html [consultado: 15/03/2021]

104 | Cosmopolitismo y nación: Juguemos en el mundo de María Elena Walsh [Verónica P. Pittau] 